\title{
Identifying Financial Bubbles Using Finite-time Singularity GARCH Model: A Case Study of Tehran Stock Exchange
}

\author{
Mahmoud Taherian ${ }^{1}$ \\ Mehrzad Minouei2 \\ ${ }^{1}$ graduate Master's Degree in Industrial Management- Financial Trend in Islamic Azad University, Central Tehran Branch \\ ${ }^{2}$ Assistant Professor of Industrial Management, Islamic Azad University, Central Tehran Branch
}

\section{Doi:10.5901/mjss.2016.v7n4s2p109}

\begin{abstract}
The purpose of this study was to identify financial bubbles using finite-time singularity GARCH model in the case study of Tehran Stock Exchange for the period 2004 to 2013. Statistical sample of study included 102 manufacturing companies listed in Tehran Stock Exchange Tehran. To achieve to this goal, two hypotheses were proposed. To test the hypotheses, DickeyFuller test, GARCH model $(1,1)$ vector auto-regression, and BEKK method were used. The results of this study suggest that both hypotheses were confirmed, in other words, in the financial bubbles situation, autocorrelation of stock returns is significant. I addition, by adding a regression component to see the possible positive feedback effects of price on return or return on stock return, we can see the returns autocorrelation in $\operatorname{GARCH}(1,1)$ model.
\end{abstract}

Keywords: financial bubbles, GARCH models, Stock Exchange

\section{Introduction}

The essence of financial bubbles, especially on stock exchanges is based on the reaction that investor community shows toward increased prices. Increased price leads to an increase in investors' enthusiasm, increased demand and therefore prices will increase again. Increasing demand for a particular stock is the mentality of the investor community of high returns of that stock in past and their optimism to receive high returns in the future. This positive feedback increases returns on stock returns leading to growing increase in stock price more than reasonable rate. On the other hand, stock price bubble is not persistent; stock prices cannot be increased and when an increase in prices reached to critical point, growing demand comes to end. At such situation, positive feedback is replaced by negative feedback and its presence becomes clear to all by bubble burst (Grrenwood et al, 2009). As you know, for stock pricing, in addition to returns, risk is considered as a main factor. To assess the risk, there are different methods. Traditional methods of assessing risk include variance and standard deviation that are quantitative methods. Duration, convexity and beta coefficient are qualitative methods to assess the risk. The above-mentioned methods measures desirable risks, while the stock pricing is mainly based on assessment of undesirable risks. The most common criterion to measure undesirable risk is "Value at Risk" (Mokhtar, 2006). Estimation of value at risk requires a model or as a set of related assumptions with distribution of stock returns. If stock returns are normally distributed, calculation of the value at risk will be very simple. However, the assuming normal distribution of stock returns is unrealistic because empirical evidence shows that stock returns, particularly at high frequencies have non-zero skewness and kurtosis. Financial bubbles have been the subject of many scientific and industrial studies for several decades. However, a glance at history of these studies is sufficient to understand that bursting of financial bubbles have been unexpected for the public. Reversely, it is observed that the public always predicts that the growth of past prices will continue always. In other words, it can be said that the public is always following the procedures. This situation is the source of one of the phenomena of financial markets known as herd behavior in buying and selling stock. As noted above, the issue of bubble has been investigated in Tehran stock exchange using different approaches. In this regard, "finite-time singularity GARCH model" used for the first time in this thesis is better suited with herd behavior in the buying and selling of stock. (Martin Pleischi et al, 2013). Finally, this study investigates that if we can achieve accurate prediction of bubble formation in the Tehran Stock Exchange by adding regression component of positive feedback of stock returns on price and regression component of positive feedback of returns on returns to the standard model $\operatorname{GARCH}(1,1)$ 


\section{Review of Literature}

\subsection{Domestic studies}

Ali Pour (2007) investigated the rational price bubbles in Tehran Stock Exchange for the period 200 to 2007. In this study, three different tests were used to examine this issue, including unit root test, co-integration and deficit collective test. Using unit root test and co-integration, the bubble in Tehran Stock Exchange has been approved. Sultani (2007) in his doctoral dissertation examined the stock price bubbles in Tehran Stock Exchange during the period 1991 to 2005 for 70 companies listed in the stock exchange. To explore the bubble in the stock price of these companies, he used cointegration method. Examining co-integration between real price of stock of each company and real dividends for each share and using Johansen co-integration test, he explored the bubble in the stock price of these companies. Results showed that $55 \%$ of studied companies had bubble in their stock price at the confidence level of $95 \%$. In his study titled as prices bubble and capital market in lan, Torki (2008) examined the price bubble in the RALS market stock in Iran using Monte Carlo simulation method. He showed that the stock price has been deviated from its equilibrium path (the current value of expected future profits). Therefore, the presence of bubble in the Iran capital market is confirmed. In a study titled as the impact of profit smoothing in forming price bubble in Tehran stock exchange, Sarebanha et al (2013) examined the relationship between profit smoothing and price bubble. To achieve this goal, they examined 47 companies during 2008-1995. First, they distinguished smoothing companies from non-smoothing companies using Acle model. Then, they conducted the bubble test on these companies using Johansen and Juselius convergence method. Accordingly, bubbled companies were distinguished from non-bubbled companies. Then, using Chi-square test (independent), they examined the relationship between profit smoothing and price bubble. Finally, they concluded that profit smoothing and price bubble are two independent subjects and smoothing cannot be regarded as a factor leading to price bubble. In a study tilted as "the examination of the relationship between free float stock value and creation of price bubble in the companies listed in Tehran Stock Exchange, Vakili Fard et al (2010) stated that we experienced a decline in total index. By studying Tehran Stock Exchange in 2004, experts and authorities have considered many causes for this crisis in the stock exchange, while they believe that growing increase in prices in 2003 and first half of 2004 was the main cause for price decline. In a study entitled as "examination of price bubble in Tehran Stock Exchange, Saleh Abadi et al (2007) stated that the Tehran Stock Exchange after its initiation in 1989 has experienced ups and downs in its activity period, and they are related to nature of the market, indicating events occurred in the market. However, market shows severe unexpected reactions sometimes. It might be said that stock market decline in 2004 was one example in this regard. The bubble was examined in the period 2003 to 2005 in this study. After the financial crisis, most researchers searched for main causes of the crisis.studies have shown that a consensus is not formed on main reason of the crisis, while there is common view only in one case and it is before the crisis the prices increases highly. In a study titled as "unusual returns in the initial public supplies stock in the Tehran stock exchange in the conditions wit and without bubble and determining the factors affecting it, Mehrani et al (2009) stated that proper pricing of initial public supplies stock is very important for companies entering to capital market for the first time. In this study, unusual significant returns in the long-term and short-term periods in the conditions of price bubble and lack of it were examined in the Tehran stock exchange and factors affecting it were examined. The results showed the existence of short-term and long-term unusual returns in the stock of initial public supplies in the Iran capital market in the conditions of lack of price bubble and existence of short-term unusual returns in these initial supplies in the Tehran stock exchange in the conditions of price bubble. Abbasian et al (2010) in a study to identify price bubble of ordinary share of Tehran stock exchange using the current value model stated that financial markets, especially capital market are among the most important equipping tools and allocation of financial resources. Given strategic and economic importance of this market, whenever financial and economic disruption and widespread diversion happen in it, and the equipping and allocation of financial resources are faced with a serious problem. One of the factors causing this problem is price bubble. Generally, when the price of a share has great difference with its future expected price, the issue of bubble emerges in the market.

\subsection{External studies}

Blanchard and Watson (1986) believe that the bubbles can leave important real impacts by affecting fundamental factors of market and modifying the behavior of prices. For example, an asset price bubble may affect the prices of other assets, though they have no bubble. An increase in the price of an asset bubble prone to price bubble leads to increase in the value of the portfolio where the assets are invested and wealth increase. If assets are not perfect substitute for each 
other, the first effect increases the expected equilibrium return for asset having bubble and reduces the equilibrium expected return for majority of other assets. By increasing demand for goods and possibly money, the second effect causes an increase in the mean expected equilibrium return. Based on the research conducted by Watson and Blanchard, the final effect of this process is not clear. However, it would probably lead to an increase in the price of other goods and increasing reduction of fundamental value of the asset that had had bubble. Therefore, bubble in gold and housing market can lead to the weakening of the stock market. The results obtained from the research conducted by Johnson, Lindblom and platan in 2002 about the bubbles of information technology companies in 1990s show that the behavior of the market participants during the bubble period has been relatively non-rational and combination of investments has been changed. During the rapid rise in stock market value of companies, information released by companies has been the most important factor influencing the investment in both natural and legal sectors. However, this reason has been evaluated as the least important factor for the valuation of stocks of companies. Time series investigation after bubble period shows that information released in the period by companies is very important for both groups of investors. This reflects the growing importance of fundamental valuation and information in bubble period. In addition, the results showed that herd behavior is a major factor in the valuation of stock and reducing the prices. Both natural and legal investors have considered analysts' prediction effective in higher valuing of stock, but they have evaluated this factor ineffective in the market reduction. In his paper released in 2006, Hanim states that market support can be guided by changing the policies to minimize the price bubbles in the market. In addition, it increases the market profit over time. Therefore, by detecting the level of trading and price bubble size, special activities can be used to stabilize stock market price. In his article titled the real effects of capital market bubbles, Gan (2006) examined the role of bank lending in the formation price bubble. He concluded that bubbles lead to economic pressure on the banks, and eventually cause a weakening of the capital market. Gan explains that bubbles cause a shock to the financial health of banks, and ultimately reduced lending and the shortage of funds in the capital market and the recession. In its article titled managerial sales of stock and profit management during information technology companies bubble in 990s released in 2005, Hadart and Louise (2005) stated that attention of administrators to prices stocks and forcing them to sell large quantities of stock due to its increased price created an environment in which managers became so sensitive to short term performances of stock. Along with this claim, managers made the profits inflated led to domestic sale activities. Thy realized that stock price, especially in companies, during the bubble periods is associated positively with profits management and domestic sale commercial activities. In addition, they found evidence that confirms that increased stock price after the bubble period is strongly and positively correlated with profits management and domestic sale activities. In a study conducted in 2009, Greenwood and the Nagel investigated the impact of the age of the manager in the forming of price bubble. They concluded that young managers (under 35 years) had better performance than older managers so that younger managers started with lower funds, but at the peak of prices or bubble, the funds increased 4 times. This increase led to an increase in stock prices, but it causes non-normal flows. Therefore, minor shareholders helped young managers to move towards an increase in stocks. The result was that certain fraction of the money was controlled by the young managers around the peak of the market. During the reduction in the stock prices and then, young managers had no certain experience in this non-normal decline despite their weak performance. Nunez and Silva (2007) examined the presence of rational bubbles in 18 stock market using conventional co-integration and threshold co-integration models. According to estimates of both model, it was found that there we explosive in stock markets of Chile, Indonesia, Korea and the Philippines and collapsing bubbles in the stock markets of China, Brazil, Venezuela, Colombia, Chile, Indonesia, Korea and the Philippines. In a study tilted as identifying financial bubbles using finite time singularities GARCH model, Pleischi et al (2013) examined to know if auto-correlation of stock returns is significant in the bubble conditions. In addition, they examined to know if auto-correlation of returns could be seen in GARCH model $(1,1)$ by adding a regression component to see the possible positive feedback effects of price on return or return on stock return. The results showed confirmation of related hypotheses.

\section{Methodology}

The study is an applied research in terms of goal. The method of study is correlational in terms of nature and content. The study was conducted within the deductive-inductive reasoning framework. Theoretical principles of study and research literature review were obtained through library studies, articles and sites in the deductive form and collecting of data to confirm or reject hypotheses was conducted in inductive way. The population of this research includes the companies listed on the Stock Exchange. Given the diversity of stock exchange companies, type of their activity, their various sizes, etc., conditional sampling was used. This means that conditions were defined to homogenize the samples, 
and those companies were included in this study that met these conditions. Among all stock companies, companies that met the following conditions were considered as sample:

A. The company should be among the industries in which there are at least 4 companies. B. Company has been traded in the stock exchange since 2003 C. Company has not experienced fiscal year change since 2003 to 2013. D. it should not have trading lag more than 3 months. Therefore, to ensure selecting companies with high transaction volumes, companies with high transaction volumes will be selected. Sampling was conducted using elimination method by applying the conditions mentioned above. The whole sample of 102 companies was selected. To calculate the research variables, Excel software was used, and SPSS software was used to analyze the hypotheses and making conclusions of them.

\section{Research hypotheses}

Based on researcher questions, the following hypotheses have been proposed:

First hypothesis: "In financial bubbles, autocorrelation of stock returns is significant."

The second hypothesis: "by adding of one regression component to see the possible positive feedback effects of price on return on stock return, the returns autocorrelation in the model GARCH $(1,1)$ can be seen".

\section{Data Analysis}

Augmented Dickey-Fuller test was used in this study firstly to test reliability of time-series of return both for large and small companies that its results are as follows. Dickey-Fuller test was also used for conditional variance that is turbulence of returns.

$$
\begin{aligned}
& H_{0}: \rho=1 \\
& H_{1}: \rho<1
\end{aligned}
$$

If the absolute value of the calculated statistic is higher than absolute value of the critical quantity, $\mathrm{H}$ is rejected. It means that series is stationary. If it is lower, the $\mathrm{H}$ is accepted and series has randomized step process and it is nonstationary. According to the results of research, it can be stated that the time series is stationary with $95 \%$ confidence.

Table 1 - Dickey-Fuller test for time series of large companies returns

\begin{tabular}{|c|c|c|}
\hline Description & T value & Level of importance \\
\hline The Dickey-Fuller statistic value & -45.36 & 0.0001 \\
\hline
\end{tabular}

Due to higher importance level of table above, it is found that times series of monthly return of large companies is stationary.

Table 2 - Dickey-Fuller test for time series of small companies returns

\begin{tabular}{|c|c|c|}
\hline Description & T value & Level of importance \\
\hline The Dickey-Fuller statistic value & -46.80 & 0.0001 \\
\hline
\end{tabular}

Due to higher importance level of table above, it is found that times series of monthly return of small companies is stationary.

Table 3 - Dickey-Fuller test for time series of price of large companies price

\begin{tabular}{|c|c|c|}
\hline Description & T value & Level of importance \\
\hline The Dickey-Fuller statistic value & -40.55 & 0.000 \\
\hline
\end{tabular}

Due to higher importance level of table above, it is found that times series of monthly price of large companies is stationary. 
Table 4 - Dickey-Fuller test for time series of price of small companies price

\begin{tabular}{|c|c|c|}
\hline Description & T value & Level of importance \\
\hline The Dickey-Fuller statistic value & -82.96 & 0.0001 \\
\hline
\end{tabular}

Due to higher importance level of table above, it is found that times series of monthly price of small companies is stationary.

First, the phenomenon of fluctuation in returns was examined that is second hypothesis of the study. As mentioned in the previous chapter, to test price phenomenon in returns, vector auto regression was used.

\subsection{Second hypothesis testing}

The second hypothesis: "by adding one regression component to see the possible positive feedback effects on return, autocorrelation of returns in the GARCH model can be seen $(1,1)$.

Table 5- criterion test to select optimal number of lag

\begin{tabular}{|c|c|c|c|c|c|}
\hline Lag & LR & FPE & AlC & SC & HQ \\
\hline 0 & NA & 0.000204 & -2.819454 & $-2.814455^{*}$ & -2.817631 \\
\hline 1 & 20.84935 & 0.000203 & -2.825062 & -2.810065 & $-2.819594^{\star}$ \\
\hline 2 & 10.61733 & 0.000203 & -2.826212 & -2.801217 & -2.817099 \\
\hline 3 & 7.495149 & 0.000203 & -2.826002 & -2.791009 & -2.813243 \\
\hline 4 & 10.73887 & 0.000203 & -2.827214 & -2.782222 & -2.810809 \\
\hline 5 & $10.26895^{\star}$ & $0.000203^{\star}$ & $-2.828223^{\star}$ & -2.773234 & -2.808173 \\
\hline 6 & 7.370373 & 0.000203 & -2.827967 & -2.76298 & -2.804272 \\
\hline 7 & 2.376133 & 0.000203 & -2.825525 & -2.750539 & -2.798184 \\
\hline 8 & 5.503198 & 0.000203 & -2.824455 & -2.739471 & -2.793468 \\
\hline
\end{tabular}

The table above examines optimal lag based criteria of Akaike, Schwartz, final prediction error, Hannan Quinn and RL ratio. Based on results, it is found that the optimal number of lags to examine returns fluctuations is 5-month lag, since Akaike criterion has the minimum value in this lag. Therefore, returns fluctuations model with 5 lags is tested.

Table (6) Price fluctuations and return on return using a Vector Autoregressive model

\begin{tabular}{|l|c|c|}
\hline \multicolumn{2}{|c|}{ Dependent variable of stocks return on companies } \\
\hline Description & Coefficient & T value \\
\hline Latitude & 0.009954 & $3.85286^{*}$ \\
\hline Large company return with one-month lag & 0.053830 & $2.87562^{*}$ \\
\hline Large company return with two-month lag & 0.017094 & 0.91336 \\
\hline Large company return with three-month lag & 0.032747 & 1.75016 \\
\hline Large company return with four-month lag & 0.010185 & 0.54446 \\
\hline Large company return with five-month lag & 0.029258 & 1.56539 \\
\hline Small company return with one-month lag & 0.022274 & 1.06948 \\
\hline Small company return with two-month lag & 0.037215 & 1.78675 \\
\hline Small = company return with three-month lag & 0.019927 & 0.99976 \\
\hline Small company return with four-month lag & 0.018383 & 0.92335 \\
\hline Small company return with five-month lag & -0.019624 & -0.9863 \\
\hline *Statistically significant coefficients are marked with this symbol. & & \\
\hline
\end{tabular}

According to the table above, it becomes clear that the coefficient value of monthly returns of companies with one-month lag is significant statistically and this indicates that the return of companies (the dependent variable) is a function of price and lagged return of companies. It means that return of companies with one-month lag follows the price. Therefore, it can be said that there is fluctuation in monthly return of companies Therefore, based on the results, the second hypothesis is confirmed. 


\subsection{First hypothesis testing}

To test the first hypothesis, two methods have been used. 1) Vector autoregressive and 2) KKEB method that are presented respectively and their results are provided as follows:

First hypothesis: "In financial bubble conditions, auto-correlation of stock returns is significant".

Table (7): Criterion to select optimal number of lag

\begin{tabular}{|c|c|c|c|c|c|}
\hline Lag & LR & FPE & AlC & SC & HQ \\
\hline 0 & NA & $9.11 \mathrm{e}-11$ & -17.4437200 & -17.4387300 & -17.4419000 \\
\hline 1 & $13986.12^{\star}$ & $2.07 \mathrm{e}-13^{\star}$ & $-23.53176^{*}$ & $-23.51677^{*}$ & $-23.52629^{\star}$ \\
\hline 2 & 1.451220 & $2.07 \mathrm{e}-13$ & -23.5289100 & -23.5039400 & -23.5198100 \\
\hline 3 & 6.177801 & $2.07 \mathrm{e}-13$ & -23.5281200 & -23.4931700 & -23.5153800 \\
\hline 4 & 5.987440 & $2.08 \mathrm{e}-13$ & -23.5272600 & -23.4823200 & -23.5108700 \\
\hline 5 & 6.945029 & $2.08 \mathrm{e}-13$ & -23.5268100 & -23.4718800 & -23.5067900 \\
\hline
\end{tabular}

The table above examines optimal lag based on criteria of Akaike, Schwartz, final prediction error, Hannan Quinn and RL ratio. Based on results, it is found that the optimal number of lags to examine turbulence of turbulences is one-month lag, since Akaike criterion has the minimum value in this lag. Therefore, turbulence of turbulences model with one lag is tested.

Table 8- investigation of autocorrelation fluctuations of stock returns of companies using Vector Autoregressive model

\begin{tabular}{|l|}
\hline Description \\
\hline Latitude \\
\hline Large company turbulence with one-month lag \\
\hline small company turbulence with one-month lag \\
\hline
\end{tabular}

Statistically significant coefficients are marked with this symbol.

\begin{tabular}{|c|c|}
\hline Coefficient & T value \\
\hline-0.000495 & -0.99002 \\
\hline 0.065032 & $3.24616^{*}$ \\
\hline 0.909237 & $709.535^{\star}$ \\
\hline
\end{tabular}

$0.909237-709.535^{*}$

Based on this method and results obtained by table above, it becomes clear that stock returns of companies are function of financial bubble and this suggests that autocorrelation of stock returns is significant. Therefore, the first hypothesis is confirmed.

\subsection{Analysis by using KKEB method}

First hypothesis: "In financial bubbles, autocorrelation of stock returns is significant."

The second hypothesis: "by adding of one regression component to see the possible positive feedback effects of price on return on stock return, the returns autocorrelation in the model GARCH $(1,1)$ can be seen".

Table 9: the bubble phenomenon has impact on stock price of companies and price affects stock return of companies

\begin{tabular}{|c|c|c|c|}
\hline Description & Coefficients & Z value & Level of importance \\
\hline $\mathrm{M}(1,1)$ & 0.00000416 & 7.476237 & 0.0000 \\
\hline $\mathrm{M}(1,2)$ & 0.076434 & 0.799879 & 0.4476 \\
\hline $\mathrm{M}(2,1)$ & 0.087754 & 17.56432 & 0.0000 \\
\hline $\mathrm{M}(2,2)$ & 0.000076 & 6.997533 & 0.0000 \\
\hline $\mathrm{A} 11(1,1)$ & 0.734401 & 10.96846 & 0.0000 \\
\hline $\mathrm{A} 12(1,2)$ & $3.86 \mathrm{E}-07$ & 0.820857 & 0.4117 \\
\hline $\mathrm{A} 21(2,1)$ & 0.812461 & 2.827321 & 0.0047 \\
\hline $\mathrm{A} 22(2,2)$ & 0.136175 & 302.0474 & 0.0000 \\
\hline $\mathrm{B} 11(1,1)$ & 0.621545 & 7.674635 & 0.0000 \\
\hline $\mathrm{B} 12(1,2)$ & 0.545527 & 7.200345 & 0.0000 \\
\hline $\mathrm{B} 21(2,1)$ & 0.089786 & 12.09786 & 0.0000 \\
\hline $\mathrm{B} 22(2,2)$ & 0.454533 & 5.986336 & 0.0000 \\
\hline
\end{tabular}


Table above is used to test first and second hypotheses using KKEB models and to test both hypotheses simultaneously. GARCH coefficient matrix that is the matrix $B$ is as follows. We note that number 1 means bubble and number 2 means return.

$\mathrm{B}=\left[\begin{array}{ll}0.6215 & 0.5455 \\ 0.0897 & 0.4545\end{array}\right]$

The matrix above shows the numbers, while by considering significance of each of coefficients, we conclude that: $\mathrm{B}=\left[\begin{array}{cc}0.6215 & 0.0 \\ 0.0897 & 0.4545\end{array}\right]$

As it is seen, the matrix above is triangular. According to the coefficient of elements (B21), it can be concluded that the bubble (1) explains the fluctuations of return (2). Thus, the first hypothesis is confirmed.

As element (B12) became statistically significant, GARCH coefficients matrix that is matrix B is as follows. We should note that number 1 represents the price and number 2 represents return.

$\mathrm{B}=\left[\begin{array}{ll}0.5455 & 0.0897 \\ 0.4545 & 0.4545\end{array}\right]$

The matrix above shows the numbers, while by considering significance of each of coefficients, we conclude that:

$\mathrm{B}=\left[\begin{array}{cc}0.5455 & 0.0 \\ 0.4545 & 0.4545\end{array}\right]$

As it is seen, the matrix above is triangular. According to the coefficient of elements (B22), it can be concluded that the price (1) explains the fluctuations of return (2). Thus, the second hypothesis is confirmed.

\section{Conclusion}

The objective of this study is to identify financial bubbles using GARCH model of finite time singularities in a case study of Tehran Stock Exchange. To reach this goal, GARCH model and BEKK method were tested. Therefore, information related to price and stock return during the 2004 to 2013 was collected and analyzed. Augmented Dickey-Fuller test was used firstly to test reliability of return time series for both large and small companies. The obtained results indicate that the related data are reliable. In addition, for conditional variance of return that Is turbulence of returns, Dickey-Fuller test was used. Then, GARCH $(1,1)$ model was used to see the possible positive feedback effects of price return or return on stock return by adding one regressive components. Results suggest that the second hypothesis of study is confirmed. Then, using GARCH model and vector auto regression and KKEB method, we examined that if auto-correlation of stock return is significant in the financial bubble conditions. Results showed that stock returns auto-correlation is significant in the financial bubble conditions. Therefore, the first hypothesis of this study is confirmed.

\section{References}

Torki, L, Mohamad, V, (2008), bubble of prices and capital market of Iran, Isfahan University Research Journal, Volume 31, Number 3 , P 207

Sareban, MR, Amiri, E, Molaee Nejad, M, A "the effect of smoothing of profits in the formation of price bubble in the Tehran Stock Exchange" Accounting Research, summer of 2013

Soltani, A (12007), examining price bubbles of stock in Tehran Stock Exchange during 1991 to 2005; Business Management Dissertation, Shahid Beheshti University of Tehran.

Saleh Abadi, A, Dalirian, H, 2010 "The price bubble in Tehran Stock Exchange" Stock Exchange Quarterly, No. 9, Spring 89, third year.

Abbasian E., Mahmoudi, V, Farzaneghan, E, 2010"Identification of common stock price bubble of Tehran Stock Exchange using the current value model" accounting and auditing studies, Volume 17, Number 60

Ali Pour, S. (2007), investigating the existence of rational price bubbles in the Tehran Stock Exchange, master thesis in business management, University of Mazandaran.

Vakili Fard, HR, Talebnia, G, Kiani, M, "to study the relationship between free float stock value with price bubble creation in companies listed in the Tehran Stock Exchange" Journal of Financial Engineering and portfolio management / Fall 2010

Mehrani, S, Asghari, MR, Tahriri, A, Ghanji, HR, 2009 "investigating the presence of abnormal returns in initial public supplies of stock on the Stock Exchange of Tehran in the presence and absence of price bubbles and determining the factors influencing it," Journal of the Stock Exchange, second year, No 8, winter2009

Blanchard ,Oliver and Watson Mark W. J. (1986) ,"Bubbles, Rational Expectations and Financial Markets".

Grrenwood, Robin. Nagel Stefan.(2009), "Inexperienced investors and bubble". Jornal of Financial Economics.

Huddart Steven, Louis Henock.(2005), "Manageriyal stock sales and earnings management during the 1990s stock market bubble" . The Pensylvania State Uinversity. 
Johnsson Mohena and Lindblom Henrik and Platan Peter, (2002), "Behavioral Finance, and the change of investors behavior during and after the speculation. Bubble at the end of the 1990s", Masters Thesis in Finance, Lund University.

Gan , Jie.(2006), "The Real Effects of Asset Market Bubble." Hong KONG University of Science and Technology

Grrenwood, Robin. Nagel Stefan.(2009), "Inexperienced investors and bubble". Jornal of Financial Economics.

Martin Pleischi, Erich Walter Farkas, Didier Sornette 2013 " Detection of financial bubbles with the FTS-Garch model and extensions" Master Thesis for the Master of Science in Quantitative Finance , University of zurich

Mokhtar, Suraya Hanim. (2006), "Detecting Rationa Speculativel Bubble In The Malaysian Stock Market". University Putra Malaysian, Serdang

Nunes, Mauricio \& Sergio, D.Silva2007. Rational Bubbles in Emerging Stock Markets, MPRA Paper2007; 4641: 1-10. 